\title{
An Unusual Presentation Of Metastatic Testicular Tumour
}

\author{
SJ Barton, DA Ashdown, S Ganta, D Wallace
}

\begin{abstract}
We report a unique case of metastatic malignant teratoma from an undescended testis which presented with acute pulmonary embolism. After chemotherapy, the undescended right testicle was resected along with a cord of non- obstructing inferior venal caval tumour which extended into the right atrium with tumour floating free within the atrium at the end of the cord of tumour. The presentation, diagnosis and treatment of testicular tumours is described and the literature pertaining to testicular tumours in military personnel reviewed.
\end{abstract}

\section{Case Report}

A 21 year old civilian male presented to accident and emergency with chest pain and shortness of breath. On examination he was tachycardic, tachypnoeic and hypoxic on room air. On chest auscultation he had globally poor air entry, but no wheeze or focal abnormality. Plain chest radiography showed possible "cannon ball" lung metastases as well as atelectasis, pleural 'wedge-shape' densities and blunting of the costophrenic angles, all suggestive of pulmonary embolism. A provisional diagnosis of pulmonary embolism secondary to metastatic malignancy was made and the patient commenced on therapeutic dose low molecular weight heparin. On further clinical examination, despite normal secondary sexual characteristics and a left-sided incision from a childhood groin exploration there was no evidence of scrotal or inguinal testes.

Thoracoabdominal CT scanning confirmed lung metastases (Figure 1) and revealed a suspicious liver lesion, abdominal and pelvic lymphadenopathy and bilateral intraabdominal testes. Initial tumour marker concentrations were grossly elevated: $\beta$ human chorionic gonadotrophin (B-HCG) $19,079 \mathrm{mIU} / \mathrm{ml}(<5 \mathrm{mIU} / \mathrm{ml}), \partial$-fetoprotein

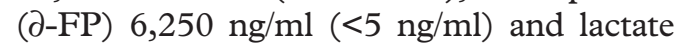
dehydrogenase (LDH) 2,000 IU/L (60-225 $\mathrm{IU} / \mathrm{L}$ ). Although there was no formal histological confirmation, the tumours markers, clinical findings and abdominal CT strongly suggested a diagnosis of metastatic non-seminomatous germ cell tumour (NSGCT).

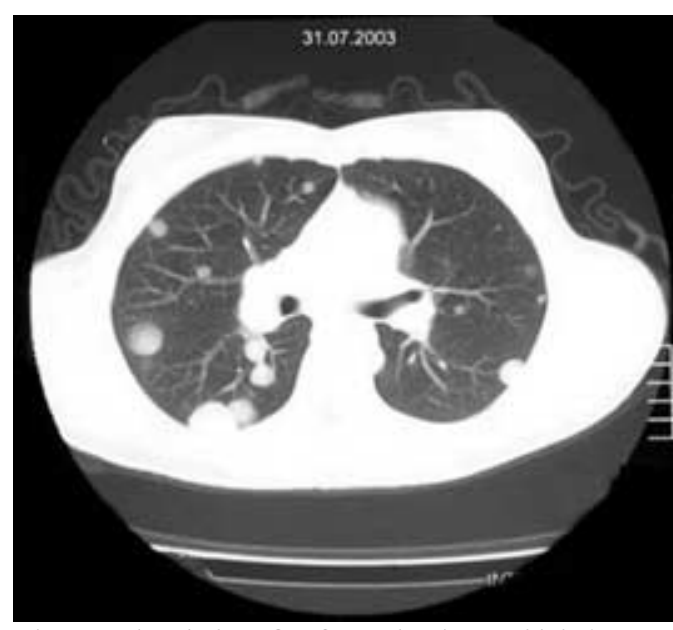

Fig 1. Patients' chest CT Scan showing multiple 'cannon ball' metastases.

His poor prognosis tumour (Stage TxN3M1b - predicting $48 \% 5$ year survival (1)) was treated with 4 cycles of bleomycin etoposide cisplatin (BEP) chemotherapy according to current guidelines (2), which returned his tumour markers to normal levels. A repeat CT scan showed regression of his liver and lung lesions, however there was a residual $6 \mathrm{~cm} \times 6 \mathrm{~cm}$ mass in the right pelvis. Surgical resection of residual masses after chemotherapy for NSCGT is recommended when tumour marker levels are normal (3). Preoperative review of his CT scans suggested an additional abnormal lucency in his right atrium, thought possibly to be a thrombus. At operation the residual pelvic mass was an enlarged right testicle at the pelvic brim, just proximal to the internal inguinal ring. After removal of the right testicle its vessels were followed to an area of dense necrotic lymphadenopathy in the inter-aorto-caval region which was also removed. A fibrous 'tether' was found to extend upwards from the insertion of the right testicular vein (Figure 2 - black arrow), to within the vena cava. Gentle traction was applied and delivered a $16 \mathrm{~cm}$ thrombus with a $3 \mathrm{~cm} \times 1.5 \mathrm{~cm}$ mass at its end (Figure 2white arrow), consisting of necrotic tumour embolus that had been floating in the right atrium. In addition, the patient underwent excision of a necrotic deposit in his liver and an atrophic undescended left testis. Histological examination of the right testis revealed predominantly necrotic tumour with some foci of differentiated teratoma and undifferentiated embryonal carcinoma. The left testes showed no evidence of cancer or carcinoma-in-situ. 


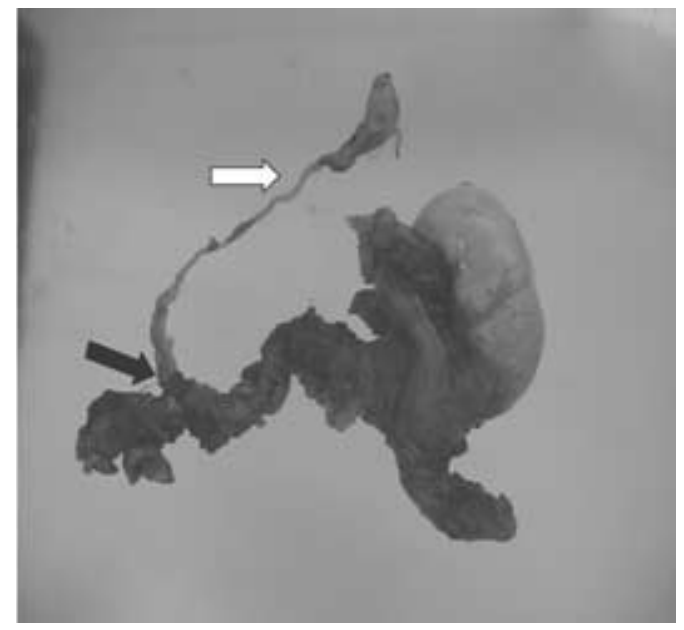

Fig 2. Right testicle showing termination of testicular vein (black arrow) and intracaval thrombus, which extended into the right atrium, with tumour embolus at its end (white arrow).

\section{Discussion}

Testicular cancer is rare, accounting for only $1 \%$ of male cancers in the United Kingdom (UK), but it is the most common solid tumour affecting men in 15-35 year-old age range, with an incidence, which is increasing in both the civilian and military population, of 3-6 cases annually per 100,000 males (4$6)$. In the UK this equates to approximately 1400 new cases diagnosed per year. In the Armed Forces, it is the commonest malignancy after lymphoma (7). This case represents a rare presentation of testicular malignancy but as the average age of active duty personnel is included in the age range of those most at risk of testicular cancer, it is important that military physicians are aware of both the common and more esoteric presentations of testicular cancer $(7,8)$. Our case represents the first report of a patient with a testicular tumour presenting with a non-obstructing vena caval thrombus with tumour attached to its free end floating in the right atrium.

The commonest presentation of testicular cancer is painless enlargement of the testicle $(4,9)$, whilst approximately $10 \%$ present with an acute scrotum, probably due to intratesticular haemorrhage or infarction $(9,10)$. It may also be diagnosed after an episode of trauma because it brings the underlying tumour to the attention of the physician (11). Around $10 \%$ of all testis tumours occur in undescended testes. Cryptorchid testes have a $3-5 \%$ chance of developing cancer, with intra-abdominal testes having the highest risk of malignant transformation (5). Around 10\% of patients will present with symptoms of metastatic disease. The commonest sites for secondary spread are lung $(89 \%)$ giving dyspnoea or cough, liver $(73 \%)$, kidney $(31 \%)$, bone $(30 \%)$ and brain (30\%) (12) although a plethora of rarer presentations have all been reported (13-18).

Testicular cancer metastasis to the retroperitoneum can present with a number of complications due to invasion or obstruction of adjacent structures (19), including inferior vena cava obstruction (IVC), commoner with right sided tumours and associated with symptomatic pulmonary embolism in $29 \%(20,21)$. IVC thrombosis from a testicular tumour, intracaval floating NSGCT, propagation of IVC thrombus into the right atrium with free-floating thrombus, and metastases to the tricuspid valve by haematogenous spread (22-26) have all been reported. Nonobstructing IVC thrombus with tumour floating in the right atrium at its free end has not previously been described. Pulmonary embolism as a complication of metastatic testicular cancer is well documented and may be the cause of sudden unexpected death in affected young men (19, 27, 28), with emboli developing from a combination of IVC invasion and hypercoagulability of malignancy (12). The management options for vena cava thrombosis complicating metastatic testicular tumour, include anticoagulation, chemotherapeutic cytoreduction, inferior vena caval filters and retroperitoneal tumour resection with en bloc resection of the IVC $(20,27,29,30)$.

\section{Diagnosis and Treatment}

After finding a suspicious scrotal lesion the spermatic cord and scrotal skin should be checked for involvement, as well as the contralateral testes and the abdomen, chest and cervical regions for signs of metastases (10). Scrotal ultrasound confirms the presence of an intratesticular mass and serum tumour markers ( $\partial$-fetoprotein, $\beta$ HCG and LDH) should be measured. Radiological staging requires CT of the chest, abdomen and pelvis (2). Radical inguinal orchidectomy remains the standard for diagnosis, provision of a detailed pathological analysis, staging and treatment of testicular neoplasms $(31,32)$.

The further treatment of testicular cancer depends on tumour histology and stage and the wishes and motivation of the patient (3, 32). The commonest staging system is that of the Royal Marsden Hospital which classifies tumours into four broad stages (32). Patients with advanced tumours are treated with primary chemotherapy. Patients with lower stage tumours undergo orchidectomy and are then either put on surveillance, receive chemotherapy or radiotherapy or further surgery to retroperitoneal lymph nodes. Survival rates are high and with the application of multimodal therapy including effective chemotherapeutic regimes, cure rates of more than $95 \%$ can be achieved (33). For stage 1 seminomas and NSGCT's cure rates approach $100 \%$, reinforcing the fact that the earlier a testicular tumour is diagnosed and treated, the better. 


\section{Testicular cancer in the military and the role of self examination}

Studies of servicemen with testicular cancer have shown that blame for delay in diagnosis is shared by the patient, general practitioners and hospital specialist. $(7,34)$. The typical delay in treatment from recognition of the lesion by the patient to definitive therapy ranges from 3-6 months and correlates with the incidence of metastases (9). Price et al in a large study of 140 testicular cancers treated by the Army Medical Services showed that $44 \%$ of cases had primary treatment delayed by more than one month because of men's failure to report symptoms (7). The study did not comment if the delay was because of the men's embarrassment in seeking help or lack of knowledge, however testicular health promotion could alleviate both problems. The authors also noted that $16 \%$ of cases had treatment delayed by the same period because of slow referral. This emphasises the fact that all medical officers should be vigilant of possible testicular tumours and aware of the appropriate management and referral pathways. Although recent diagnostic and therapeutic developments have greatly improved the prognosis in this disease, continued delay in diagnosis will impact on further possible improvements in survival. Screening for testicular cancer is not recommended as the overall incidence of testicular cancer is low and survival excellent. Testicular self examination (TSE) and testicular health awareness is, however, promoted by the major cancer charities although the evidence to support TSE is scarce. It may provoke unwarranted anxiety and unnecessary medical interventions (35), although other authors suggest providing more information on testicular cancer and TSE may reduce the number of men requiring toxic treatment and major surgery and may even reduce mortality (36). Certainly improving health awareness and teaching TSE in at risk groups may be beneficial and studies suggest most men would be willing participants (37). An Israeli army study reported that few soldiers are shown TSE, only $2 \%$ practised it regularly and $24 \%$ had never examined their testicles before (38). In the same study army physicians were questioned about physical examinations they carried out on soldiers, and of 200 questioned, only $10 \%$ routinely examined testicles

Research has indicated that most men do not know the importance of TSE, and confirms the need for both patient education and physician awareness of the potential seriousness of all testicular masses or adult cryptorchidism $(12,39)$.

\section{Conclusion}

The military medical officer should take advantage of entrance and routine medicals to check for undescended or abnormal testicles and to improve patient awareness of testicular cancer and teach testicular self examination. Our case, although reporting a unique presentation of the disease, highlights many areas of concern of relevance to physicians caring for a predominantly male service population. Physicians are reminded that vague presentations of ill health in males should prompt examination of the external genitalia, and that an empty scrotum should be investigated in the absence of a clear history of orchidectomy.

\section{References}

1. ICCCG. International germ ell consensus classification: a prognostic factor-based staging system for metastatic germ cell cancer. $\mathcal{F}$ clin Oncol. 1997; 15:594-601.

2. Jones RH, Vasey PA. Part I+II: testicular cancermanagement of advanced disease. The Lancet Oncology. 2003; 4: 730-747.

3. Laguna M P, Pizzocaro G, Klepp O, Algabs F, Kisbenedek L, Leiva O, UA Working group on Oncological Urology. EAU Guidelines on Testicular Cancer. Eur Urol. 2001;40;102-110.

4. Tiptaft RC. Testis, epididymus and scrotum. In Burnard KG, Young AE (eds) The New Aird's Companion in Surgical studies, 2nd edition. London: Churchill Livingstone, 1998: 1135.

5. Richie JP. Neoplasms of the testis. In: Walsh PC Retik AB, Stamey TA, Vaughan ED (eds) Campbell's Urology, 6th edition. Philadelphia:W.B. Saunders Company, 1992: 1222-1263.

6. Dearnaley DP, Huddart RA, Horwich A. Managing testicular cancer. BMF 2001; 322:1583-1588.

7. Price BA, Shepherd AF, Peters NH. 12 Year Review of Testicular Tumour Treatment by the Army Medical Services. F $R$ Army Med Corps. 1993; 139:89-93.

8. Kelty P, Frazier H, O'Conell K, Ghosh BC. Germ cell testis cancer: 15-year review. F Surg Oncol. 1996; 62(1): 30-3.

9. Presti JC. Genital tumours. In: Tanagho EA McAninch JW (eds).Smith's General Urology, 15th edition. San Francisco: Lange Medical, 2000:422-430.

10. Parra Muntaner L. Acute scrotum secondary to testicular tumour. Arch Esp Urol. 2002; 55(1) :71-3

11. Klein A. Testicular tumours in adults. In: Reisnick MI, Novick A (eds).Urology Secrets, 3rd edition. Philadelphia: Hanley and Belfus, 2003:110-118.

12. Post GJ, Belis JA. Delayed presentation of testicular tumours. South Med F. 1980;73(1):33-5.

13. Stokes EW, Perkins C, Testicular choriocarcinoma. An unusual presentation as occult gastrointestinal blood loss. F Adolesc Health Care. 1989;10(2):14650.

14. Plummer ER, Greene DR, Roberts JT. Seminoma metastatic to the prostate resulting in rectovesical fistula. Clin Oncol. 2000;12(4):229-30.

15. Hofflander R, Beckes D, Kapre S, Matolo N, Liu S. A case of jejunal intussusception with gastrointestinal bleeding caused by metastatic testicular germ cell cancer. Dig Surg 1999;16(5):439-40.

16. Haab F, Cour F, Boutan Laroze A, Squara P, Lucas G. testicular neoplasm presenting as a major pulmonary embolus. Eur Urol. 1996; 29(4):494-6.

17. Gale J, mead GM, simmonds PD. Management of spinal cord and cauda equine compresson secondary to epidural metastatic disease in adults with malignant germ cell tumours. Clin Oncol. 2002;14(6):481-90.

18. Nabi G, Dogra PN. Fungating scrotal mass. Rare presentation of testicular tumour. Urol Int. 2002;69(3):236-7.

19. Leslie JA. Stegemann L, Miller AR.Thompson IM. Metastatic seminoma presenting with pulmonary embolus, inferior vena caval thrombosis, and gastrointestinal bleeding. Urology 2003; 62(1):144. 
20. Hassan B, Tung K, Weeks R, Mead GM. The management of inferior vena cava obstruction complicating metastatic germ cell tumours. Cancer 1999; 85(4): 912-8.

21. Adsan O, Muftuoglu YZ, Suzer O, Beduk Y, Thrombosis of the inferior vena cava by a testicular tumour. Int Urol Nephrol.1995; 27(2): $179-82$.

22. Savarese DM, Rohrer MJ, Pezzella AT, Davidoff A, Fraire AE. Successful management of intracardiac extension of tumour thrombus in a patient with advanced nonseminomatous germ cell testicular cancer. Urology 1995; 46(6): 883-7.

23. Moon TD, Fox LS, Varma DG. Testicular teratocarcinoma with intracaval metastases to the heart. Urology 1992; 40(4):368-70.

24. Fishman AD, Hoffman A, Volterra F, Frymus M, Gentilluci $M$. Intracaval and intracardiac metastatic non seminomatous germ cell tumour: a rare cause of haemolytic anaemia and thrombocytopaenia. Cancer Investigation 2002; 20(7-8): 996-1001.

25. Sells H, Stewart A, Sibley GN. Intracaval mass after chemotherapy for metastatic nonseminomatous germ cell tumour. BfU Int. 2000; 85(3):374.

26. Adsan O, Muftuoglu YZ, Suzer O, Beduk Y. Thrombosis of the inferior vena cava by a testicular tumour. Int Urol Nephrol. 1995; 27(2):179-82.

27. Kwok CK, Horowitz MD, Livingstone AS, Block NL. Mature testicular teratoma with vena caval invasion presenting as pulmonary embolism. $\mathcal{F}$ Urol. 1993; 149(1):129-31.

28. Dada MA,Van Velden DJ. Sudden death caused by testicular germ cell tumour. Medicine, Science and the Law. 1995; 35(4):357-9.

29. Geffen DB, Keneti J, Hendler N, Hertzanu Y. Testicular carcinoma with inferior vena cava thrombosis extending into the right atrium treated with chemotherapy and anticoagulation. European Urology. 1992;21(1):82-4.
30. Spitz A, Wilson TG, Kawachi MH, Ahlering TE Skinner DG. Vena Caval resection for bulky metastatic germ cell tumours: an 18 year experience. F Urol. 1997;158(5): 1813-8.

31. Passarella M, Usta MF, Bivalacqua TJ, Hellstrom WJG, Davis R. Testicular-sparing surgery: a reasonable option in selected patients with testicular lesions. BfU International 2003; 91:337-340.

32. Jones Rh, Vasey PA. Testicular cancer management of early disease. Lancet Oncol. 2003; $4: 730-737$.

33. Ashdown DA, Bodiwala D, Liu S. Is high cord radical orchidectomy always necessary for testicular cancer? Ann. R. Coll. Surg. Engl. 2004;86: 289-91.

34. Attard GJ. Delay in treatment of testicular tumours in the Army. F R Army Med Corps. 1985;131(3):140-1.

35. Morris J. Health promotion. The case against TSE. NursTtimes. 1996; 92(33):41.

36. Tavolini IM, Zuliani G, Norcen M, Dal Moro F, Abatangelo G, Oliva A. Prevention and early diagnosis of testicular neoplasms. Arch Ital Urol Androl. 1999; 71(1): 27-30.

37. Moore RA, Topping A. Young men's knowledge of testicular cancer and testicular self examination: a lost opportunity? Eur $\mathcal{F}$ Cancer Care (Engl). 1999; 8(3);137-42.

38. Singer AJ, Tichler T, Orvieto R, Finestone A, Moskovitz M. Testicular carcinoma: a study of knowledge, awareness, and practice of testicular self examination in male soldiers and military physicians. Mil Med. 1993; 158(10):640-3.

39. Brown CG. Testicular cancer: an overview. Medsurg Nurs. 2003; 12(1): 37-43. 